\title{
Characterization of the insertase BamA in three different membrane mimetics by solution NMR spectroscopy
}

\author{
Leonor Morgado • Kornelius Zeth • \\ Björn M. Burmann · Timm Maier · \\ Sebastian Hiller
}

Received: 29 October 2014/ Accepted: 22 January 2015/Published online: 1 February 2015

(C) Springer Science+Business Media Dordrecht 2015

\begin{abstract}
The insertase BamA is the central protein of the Bam complex responsible for outer membrane protein biogenesis in Gram-negative bacteria. BamA features a 16-stranded transmembrane $\beta$-barrel and five periplasmic POTRA domains, with a total molecular weight of $88 \mathrm{kDa}$. Whereas the structure of BamA has recently been determined by X-ray crystallography, its functional mechanism is not well understood. This mechanism comprises the insertion of substrates from a dynamic, chaperone-bound state into the bacterial outer membrane, and NMR spectroscopy is thus a method of choice for its elucidation. Here, we report solution NMR studies of different BamA constructs in three different membrane mimetic systems: LDAO micelles, DMPC:DiC 7 PC bicelles and MSP1D1:DMPC nanodiscs. The impact of biochemical parameters on the spectral quality was investigated, including the total protein concentration and the detergent:protein ratio. The barrel of BamA is folded in micelles, bicelles and nanodiscs, but the $\mathrm{N}$-terminal POTRA5 domain is flexibly unfolded in the absence of POTRA4. Measurements of backbone dynamics show that the variable insertion region of BamA, located in the extracellular lid loop
\end{abstract}

Electronic supplementary material The online version of this article (doi:10.1007/s10858-015-9906-y) contains supplementary material, which is available to authorized users.

L. Morgado · K. Zeth · B. M. Burmann · T. Maier ·

S. Hiller $(\square)$

Biozentrum, University of Basel, Basel, Switzerland

e-mail: sebastian.hiller@unibas.ch

K. Zeth

Department of Biochemistry, University of the Basque Country, Leioa, Spain

K. Zeth

IKERBASQUE Basque Foundation for Research, Bilbao, Spain
L6, features high local flexibility. Our work establishes biochemical preparation schemes for BamA, which will serve as a platform for structural and functional studies of BamA and its role within the Bam complex by solution NMR spectroscopy.

Keywords Membrane protein - Omp85 insertase $\cdot$ NMR spectroscopy $\cdot$ Backbone dynamics $\cdot$ Bicelles $\cdot$ Nanodiscs
Abbreviations
DMPC 1,2-Dimyristoyl-sn-glycero-3-phosphocholine
$\mathrm{DiC}_{7} \mathrm{PC} \quad$ 1,2-Diheptanoyl-sn-glycero-3-phosphocholine
LDAO Lauryldimethylamine- $N$-oxide
POTRA Polypeptide transport-associated
BAM $\quad \beta$-barrel assembly machinery
OMP Outer membrane protein

\section{Introduction}

Membrane proteins are carriers of essential biological functions, including substrate transport, signalling, and protein biogenesis. They comprise two main architectural classes, with transmembrane $\alpha$-helical and $\beta$-barrel structure, respectively (White 2004). Integral $\beta$-barrel membrane proteins occur specifically in the outer membranes of Gram-negative bacteria, mitochondria and chloroplasts (Fairman et al. 2011; Walther et al. 2009). As an essential step of their biogenesis, the unfolded $\beta$-barrel outer membrane proteins (Omps) are inserted into the membrane by insertase complexes (Höhr et al. 2015; Rigel and Silhavy 2012; Selkrig et al. 2014). In the Gram-negative bacterium $E$. coli, the $\beta$-barrel assembly machinery (Bam) is responsible for the biogenesis of most Omp substrates (Fig. 1a) (Rigel and Silhavy 2012; Voulhoux and 
Tommassen 2004). Bam consists of five proteins, BamA, BamB, BamC, BamD, and BamE. BamA is an integral $\beta$ barrel membrane protein with a periplasmic N-terminal region composed of five polypeptide transport-associated (POTRA) domains (Bos et al. 2007) (Fig. 1b). The other four proteins BamB-BamE are lipoproteins, each of which is attached to the inner leaflet of the outer membrane by a lipid anchor (Sklar et al. 2007). In E. coli, two of the five Bam proteins, BamA and BamD, are essential for cell viability under laboratory conditions, however, the complex was found to function optimally only when all five proteins are present (Malinverni et al. 2006; Onufryk et al. 2005; Hagan et al. 2010).

Fig. 1 The insertase BamA and its role in bacterial outer membrane protein biogenesis, a Schematic representation of the Bam complex and its function. The Bam complex (blue) consists of the five proteins BamA-BamE. Its central component BamA features a 16-stranded transmembrane $\beta$-barrel and five periplasmic POTRA domains. BamB-BamE are lipoproteins anchored to the inner leaflet of the outer membrane. The Bam complex folds and inserts outer membrane protein substrates (green) into the outer membrane. Periplasmic holdase chaperones (purple) deliver the substrates to Bam. b Topology plot of BamA(344-810) from E. coli, comprising the domain POTRA5 (residues 344-422) and the transmembrane domain (residues 424-810). Residues with $\beta$-strand secondary structure are represented as squares, all other residues as circles. Periplasmic turns T1-T8 and extracellular loops L1-L8 are indicated. Interstrand hydrogen bonds are shown as orange lines. Residues with side chains facing the membrane are highlighted grey. The approximate position of the membrane is shown as a yellow rectangle. The positions of secondary structure elements were derived from PDB entries 4N75 (Ni et al. 2014) and 3Q6B (Zhang et al. 2011)

(b)
Structures of all Bam complex members are now available (Albrecht et al. 2014; Albrecht and Zeth 2011; Dong et al. 2012a, b; Kim et al. 2012, 2011a, b; Kim and Paetzel 2011; McMorran et al. 2014; Ni et al. 2014; Noinaj et al. 2013; Warner et al. 2011). These include several variants of periplasmic BamA POTRA domains, which can be crystallized from aqueous solution without the need for membrane mimetics (Gatzeva-Topalova et al. 2008, 2010; Kim et al. 2007; Zhang et al. 2011). Recently, the crystal structures of BamA variants from three different organisms (H. ducreyi, N. gonorrhoeae and E. coli) were determined from detergent solution and bicelles (Albrecht et al. 2014; Ni et al. 2014; Noinaj et al. 2013). The related Omp85
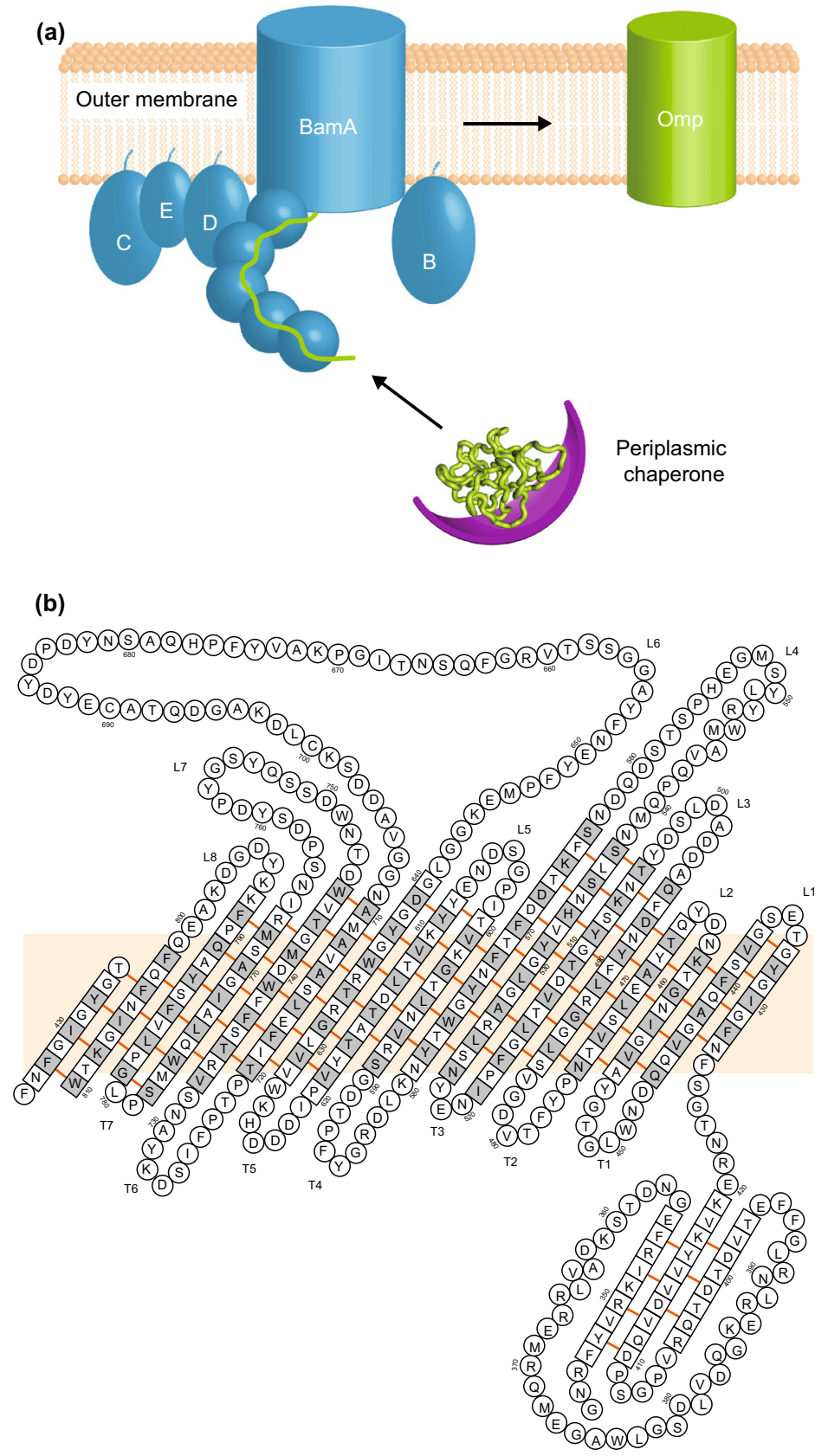
protein TamA, a protein from the Omp85 family that is involved in autotransporter biogenesis in $E$. coli was crystallized from bicelle solution (Gruss et al. 2013). The crystal structures of BamA and TamA share a highly similar structure and revealed two unique structural features that are likely part of the functional mechanism of substrate insertion: a lateral gate and a tight extracellular lid. The lateral gate is formed by the weak $\beta$-sheet pair formed between strands 1 and 16, hinting towards a putative lateral opening mechanism, where the unfolded outer membrane protein would use these strands as a template for $\beta$-augmentation, and form a hybrid BamA-Omp barrel prior to release the folded Omp into the membrane (Gruss et al. 2013). The relevance of barrel opening for BamA function has been recently highlighted by disulphide crosslinks between strands 1 and 16, making BamA nonfunctional (Noinaj et al. 2014). The second unique structural feature is a lid that closes the barrel tightly at its extracellular side (Albrecht et al. 2014; Gruss et al. 2013; Ni et al. 2014; Noinaj et al. 2013). The lid is formed by the "lid loop" L6, which is essential for BamA function (Leonard-Rivera and Misra 2012; Ni et al. 2014; Noinaj et al. 2013). The variable position of the POTRA domains relative to the barrel in different crystal forms has led to the proposal that these domains form a gate that regulates the access to the interior of the $\beta$-barrel (Albrecht et al. 2014; Noinaj et al. 2013). In contrast, solid-state NMR studies of BamA reconstituted in liposomes suggested that the POTRA domains are tightly attached to the $\beta$-barrel and have only limited mobility (Sinnige et al. 2014).

In this work, we characterize different BamA construct in LDAO micelles, DMPC:DiC 7 PC bicelles and MSP1D1:DMPC nanodiscs towards their suitability for structural and functional studies by solution NMR spectroscopy. The impact of biochemical parameters on the spectral quality is investigated, including the total protein concentration and the detergent:protein ratio. In particular, the structural conformation of the POTRA5 domain is characterized based on sequence-specific resonance assignments and by a comparison with a soluble protein construct. We find that the transmembrane $\beta$-barrel of BamA is folded in either micelles, bicelles or nanodiscs, but that the N-terminal POTRA5 domain is flexibly unfolded in solution, due to the absence of stabilizing contacts with other protein domains. These findings give important advice on the choice of suitable domain constructs for functional studies of BamA. Finally, distinct time scales of dynamic behavior were observed for the BamA $\beta$-barrel and its extracellular loop L6. Our work presents the first high-resolution 2D solution NMR spectra of the BamA barrel reconstituted in membrane mimetics and establishes improved biochemical preparation schemes, which will serve as a platform for structural and functional studies of BamA and its role within the Bam complex.

\section{Results and discussion}

The BamA barrel is folded in three different membrane mimetic systems

To facilitate solution NMR studies of BamA in aqueous solution, a protocol for the reconstitution of BamA in three different membrane mimetic systems was established (Fig. 2). A construct of BamA, comprising the POTRA5 domain and the $\mathrm{C}$-terminal transmembrane $\beta$-barrel [(BamA(344-810)] was expressed in E. coli and refolded from a chaotrope-denatured state by rapid dilution into LDAO micelles. 2D $\left[{ }^{15} \mathrm{~N},{ }^{1} \mathrm{H}\right]$-TROSY NMR spectra of BamA in LDAO micelles feature a wide dispersion of the amide proton chemical shifts (Fig. 2, orange). In particular, the region characteristic for $\beta$-strand secondary structure $(8.5-10.0 \mathrm{ppm})$ is substantially populated with resonances, indicating the formation of secondary structure and thus the conclusion that the transmembrane barrel is stably formed, in agreement with crystallization results from LDAO micelles (Albrecht et al. 2014; Ni et al. 2014). From the LDAO-solubilized state, $\operatorname{BamA}(344-810)$ was further transferred to either bicelles or lipid bilayer nanodiscs, resulting in biochemically homogeneous samples, as evidenced by monodisperse size-exclusion chromatograms (Fig. 2). 2D [ $\left.{ }^{15} \mathrm{~N},{ }^{1} \mathrm{H}\right]$-TROSY NMR of these preparations indicate that the BamA $\beta$-barrel is similarly well-folded in either of these membrane mimetics (Fig. 2, yellow and magenta).

The 2D $\left[{ }^{15} \mathrm{~N},{ }^{1} \mathrm{H}\right]$-TROSY spectrum acquired in LDAO micelles (Fig. 2, orange) features a high dynamic range of signal intensities. A set of high-intensity peaks in the random-coil region of the spectrum $\left[7.5<\delta\left({ }^{1-}\right.\right.$ $\mathrm{H})<8.5 \mathrm{ppm}]$ was on average about ten times more intense than resonances located in the spectral region typical for $\beta$-strand secondary structure $\left[8.5<\delta\left({ }^{1-}\right.\right.$ $\mathrm{H})<10 \mathrm{ppm}]$, indicating that BamA contains certain segments that experience fast local dynamics relative to the rest of the protein. In an attempt to improve the spectral quality, different sample preparations were explored (Fig. 3). Thereby, a particular focus was put on the total protein concentration, because for sequence-specific backbone resonance assignments of large membrane proteins in detergent micelles, well-resolved spectra at protein concentrations $>0.5 \mathrm{mM}$ are required. The concentration dependence of the signal intensities was quantified by measuring the average intensities of three different groups of resonances (Fig. 3): POTRA domain (purple), flexible loops (green) and transmembrane domain (blue). 


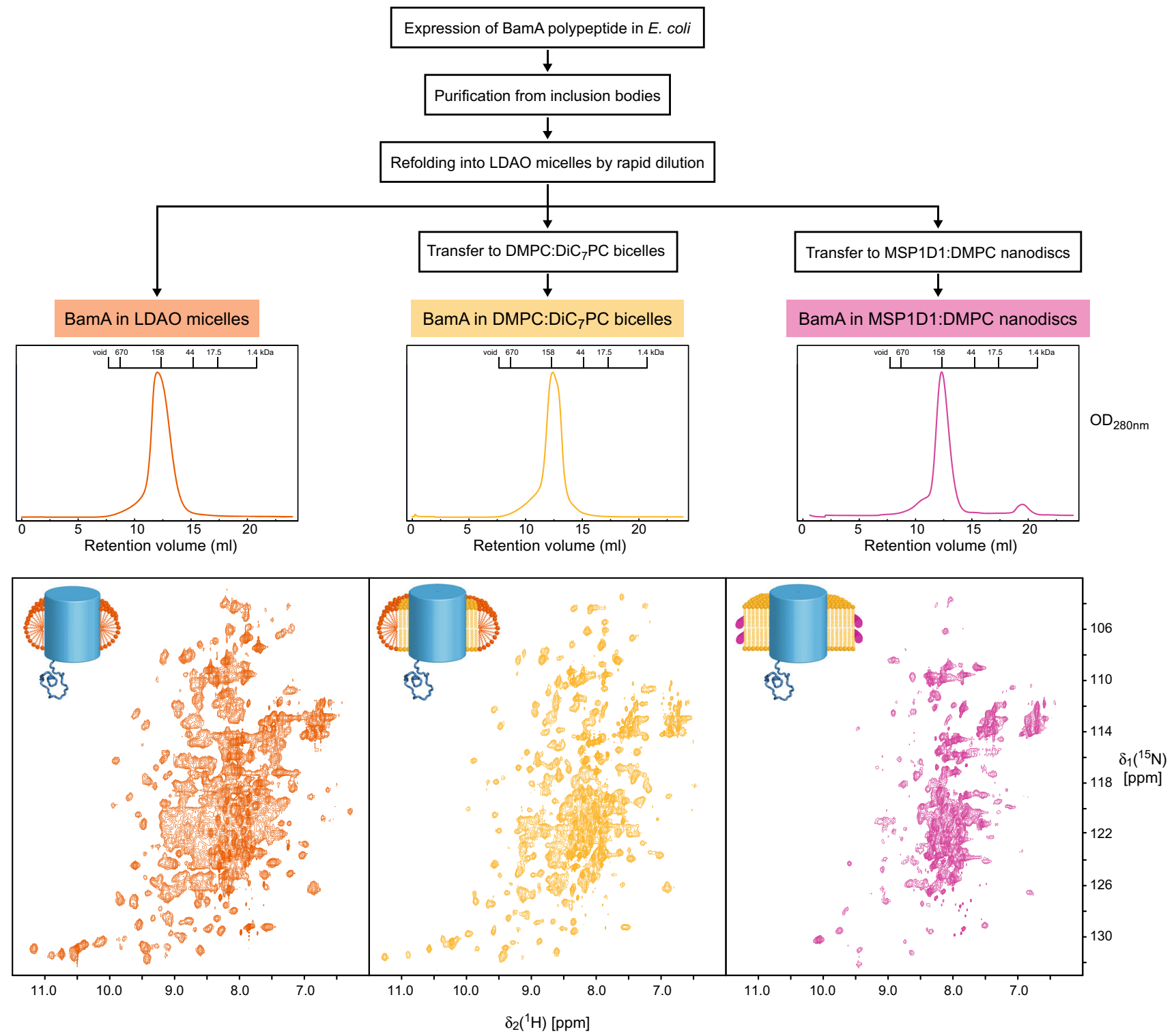

Fig. 2 Workflow for the reconstitution of BamA in three different membrane mimetic systems. Samples of BamA were reconstituted in either LDAO micelles (orange, left column), DMPC: $\mathrm{DiC}_{7} \mathrm{PC}$ bicelles (yellow, middle column), or MSP1D1:DMPC nanodiscs (magenta, right column). For each system, a representative size exclusion

The experimental sensitivity for the barrel resonances showed only a slight dependence on the protein:detergent ratio (Fig. 3b, left panel). For this parameter, a ratio of 200 molecules of LDAO to BamA was found to be ideal and used in all subsequent experiments with LDAO detergent. The sodium chloride concentration was varied in the range of 50-300 mM. At high salt concentrations, the spectral sensitivity was reduced due to the absorbance of rf-waves by the salt ions (Kelly et al. 2002). At low salt concentrations, the intensity was also reduced, presumably arising from reduced stability of the protein. The average chromatogram and a $2 \mathrm{D}\left[{ }^{15} \mathrm{~N},{ }^{1} \mathrm{H}\right]$-TROSY NMR spectrum are shown. The NMR spectra were acquired at 500, 300 and $250 \mu \mathrm{M}$ protein concentration for micelles, bicelles, and nanodiscs, respectively. Cartoons indicate the three-dimensional arrangement of the mimetic systems. See "Materials and Methods" section for details

concentration of $150 \mathrm{mM}$ sodium chloride was thus found to be the best compromise for the different domains in the protein (Fig. 3b, right panel). For the resonances from the POTRA domain, an increase in total protein concentration leads to a concomitant increase of signal intensity, but for the flexible loops and the transmembrane domain, a drastic decrease of spectral sensitivity is observed (Fig. 3c). These data thus suggest that increased concentration of the protein leads to non-specific oligomerization, which in turn affects the molecular tumbling properties of the protein and thus leads to increased line widths. Mutation of the two 
Fig. 3 Experimental sensitivity of BamA in high-resolution NMR spectra. a $2 \mathrm{D}\left[{ }^{15} \mathrm{~N},{ }^{1} \mathrm{H}\right]-$ TROSY spectrum of $\operatorname{BamA}(421-810)$ (orange) at $200 \mu \mathrm{M}$ protein concentration and of BamA(344-810) (black) at $500 \mu \mathrm{M}$, both in LDAO micelles. b-d Normalized average intensities for groups of resonance peaks as a function of biochemical parameters. The three groups are POTRA5 domain (purple), flexible loops (green) or transmembrane domain (blue). The biochemical parameters are (b)

detergent:protein ratio (left panel) and $\mathrm{NaCl}$ concentration (right panel), c total protein concentration in LDAO micelles [BamA(344-810) left panel, BamA(421-810) right panel], $\mathbf{d}$ type of membrane mimetic system [BamA(344-810) left panel, BamA(421-810) right panel]. Values were normalized relative to $0.3 \mathrm{mM}$ BamA(344-810) in $66 \mathrm{mM}$ LDAO and $150 \mathrm{mM}$ $\mathrm{NaCl}$ or $0.2 \mathrm{mM}$

$\operatorname{BamA}(421-810)$ in $50 \mathrm{mM}$ $\mathrm{LDAO}$ and $150 \mathrm{mM} \mathrm{NaCl}$ (full symbols) (a)

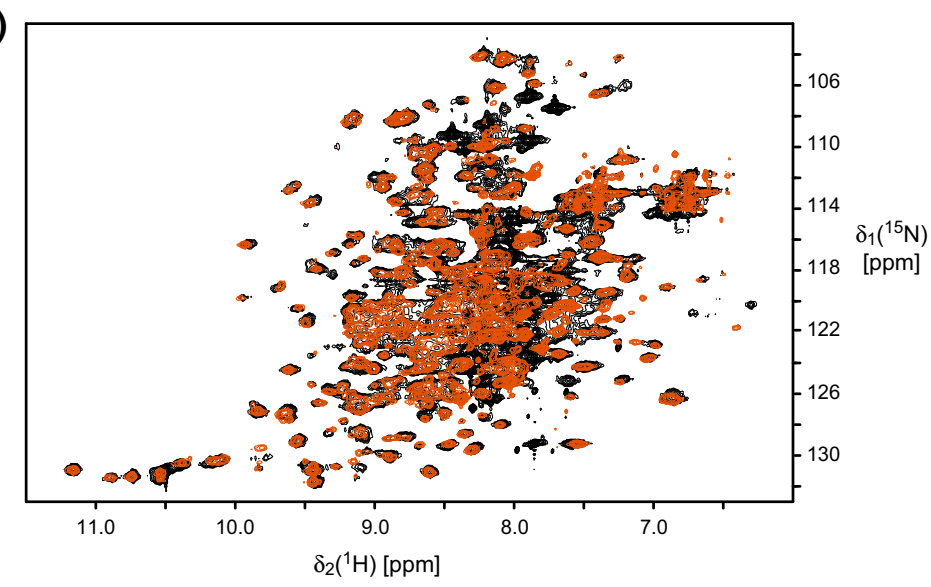

(b)
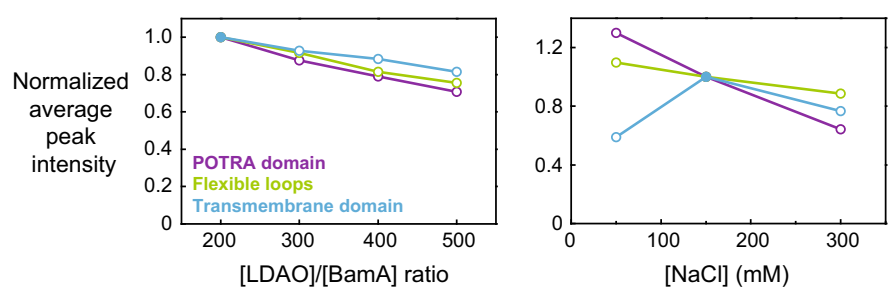

(c)
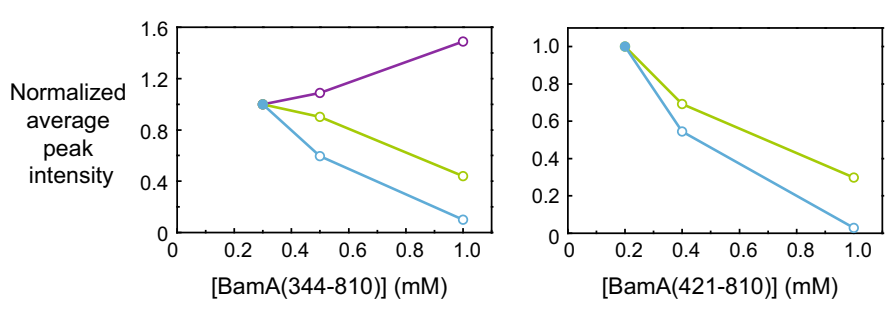

(d)

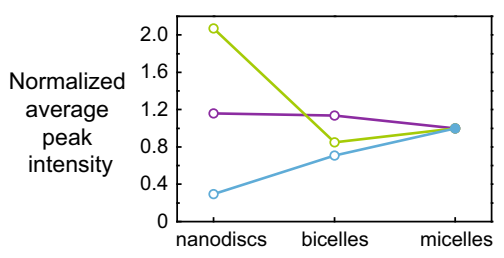

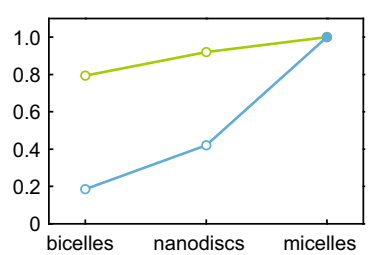

cysteine residues C690 and C700 to serines did not substantially improve the spectral quality (data not shown).

Backbone assignment of flexible segments of BamA(344-810) in LDAO micelles

The flexible parts of $\operatorname{BamA}(344-810)$ were assigned using a $\left[U-99 \%{ }^{2} \mathrm{H},{ }^{13} \mathrm{C},{ }^{15} \mathrm{~N}\right]-\mathrm{BamA}(344-810)$ sample in LDAO micelles. Analysis of the 3D TROSY-HNCACB spectrum (Fig. 4b) established unambiguous sequencespecific resonance assignments for the following segments of residues: D358-V364, T397-R404, and D410-V414. These residues are part of the POTRA5 domain (Fig. 4c), with T397-R404 and D410-V414 forming an anti-parallel $\beta$-sheet in the available crystal structures (Zhang et al. 2011). However, the secondary backbone ${ }^{13} \mathrm{C}$ chemical shifts of these residues in $\operatorname{BamA}(344-810)$ are close to random-coil values, indicating a lack of secondary structure (Fig. 4d, orange). The POTRA5 domain is thus unfolded for BamA(344-810) in LDAO micelles. This conclusion is additionally supported by a comparison with the sequence-specific assignment of a soluble [U-99\%, ${ }^{13} \mathrm{C},{ }^{15} \mathrm{~N}$ ]-POTRA4-5 construct (BamA $(263-424)$ ), in which POTRA5 is known to be folded, and which shows large secondary chemical shifts for these residues (Fig. 4d).

We then speculated that the presence of detergent might be the reason for POTRA5 being in an unfolded state. LDAO is a relatively strong detergent that can potentially denature globular protein domains. Interestingly, however, 2D $\left[{ }^{15} \mathrm{~N},{ }^{1} \mathrm{H}\right]$-TROSY spectra showed that POTRA5 of $\operatorname{BamA}(344-810)$ is also unfolded in preparations with the other two membrane mimetics investigated in this work, 
(a)

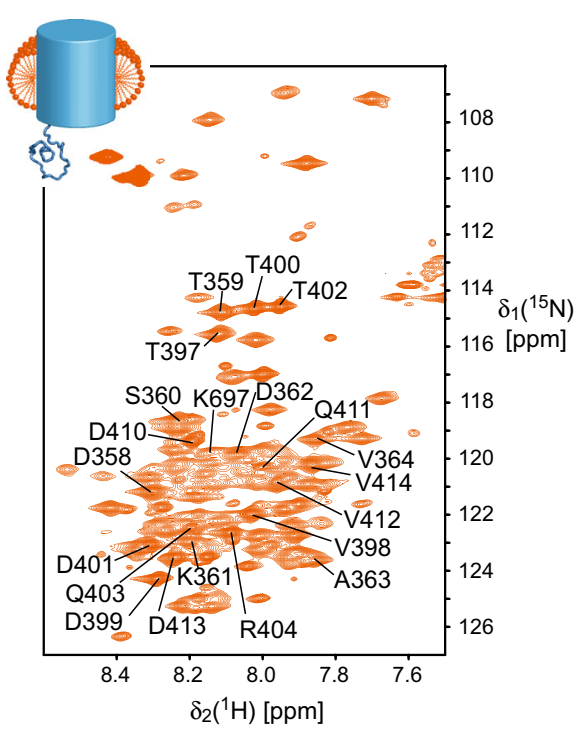

(b)

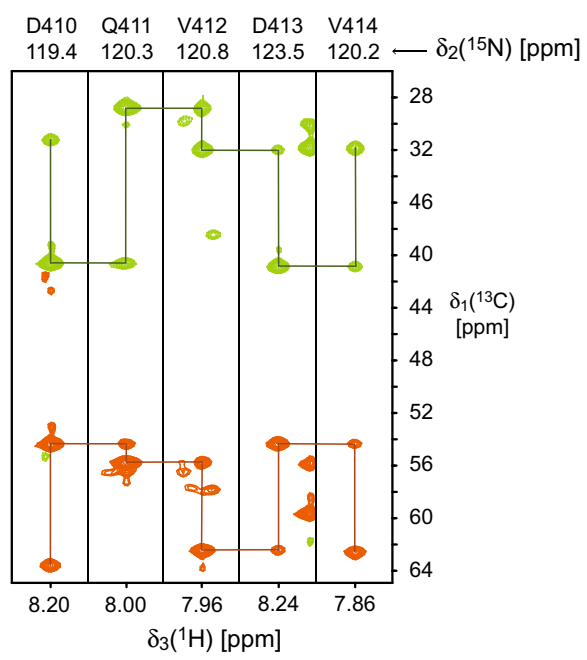

(e)

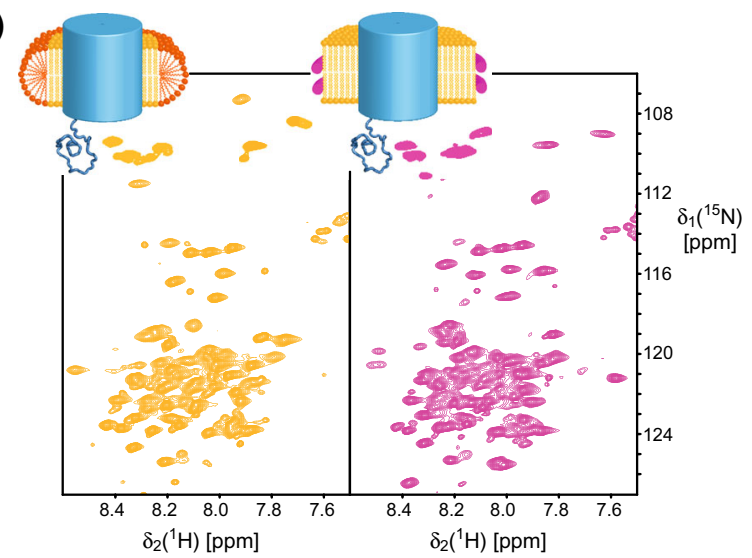

Fig. 4 The POTRA domain of $\operatorname{BamA}(344-810)$ is flexibly unfolded. a $2 \mathrm{D}\left[{ }^{15} \mathrm{~N},{ }^{1} \mathrm{H}\right]$-TROSY spectrum of $\operatorname{BamA}(344-810)$ at $1 \mathrm{mM}$ protein concentration in LDAO micelles, plotted at high contour level. Sequence-specific resonance assignments are indicated. b Strips from a 3D TROSY-HNCACB for the segment D410-V414 of BamA(344-810) solubilized in LDAO micelles. Sequential connections are indicated by horizontal lines. $\mathbf{c}$ Enlarged view of the 2D

DMPC:DiC ${ }_{7} \mathrm{PC}$ bicelles and MSP1D1:DMPC lipid bilayer nanodiscs (Fig. 4e). Since lipid bilayer nanodiscs are detergent-free, inhibition of POTRA5 folding is thus not caused by LDAO.

Another possibility was that POTRA5 did not refold properly during our preparation protocol from inclusion bodies. To test this hypothesis, we attempted to study the isolated POTRA5 domain. However, this domain did not express in E. coli, whereas analogous constructs of POTRA4 and POTRA4-5 did show overexpression (data not shown). Furthermore, we characterized a chimeric protein construct, in which POTRA5 was fused N-terminally to a GB1 solubility domain (Zhou et al. 2001), and which was topology plot of BamA. All residues for which sequence-specific resonance assignments were obtained, are highlighted blue. d Secondary ${ }^{13} \mathrm{C}$ chemical shifts of POTRA5 in BamA(344-810) (orange) and in the soluble construct POTRA4-5 in aqueous buffer (blue). e $2 \mathrm{D}\left[{ }^{15} \mathrm{~N},{ }^{1} \mathrm{H}\right]$-TROSY spectra of $\operatorname{BamA}(344-810)$ in DMPC:DiC 7 PC bicelles (orange) and MSP1D1:DMPC nanodiscs (magenta)

purified directly from the soluble fraction of $E$ coli. Whereas GB1 is well folded in detergent-free buffer, the resonances of the POTRA5 domain feature random coil chemical shifts, showing that POTRA5 is not folded in this construct (Fig. S1).

The inhibition of POTRA5 folding in the POTRA5barrel construct is thus not caused by detergent and not by defective refolding. Folded forms of POTRA5 have so far been observed in crystal structures of protein constructs that contained the POTRA4 domain adjacent to POTRA5, which features strong stabilizing side chain contacts at the POTRA5-POTRA4 interface (Gatzeva-Topalova et al. 2010; Zhang et al. 2011), and in a crystal form of a 
construct POTRA5-BamA-barrel, where POTRA5 was stabilized by non-natural crystal contacts with the extracellular side of the BamA barrel (Albrecht et al. 2014). Importantly, in the latter structure, crystallographic B-factors are particularly high for the POTRA5 domain, indicating increased dynamics, possibly in combination with conformational heterogeneity (Fig. S2). Overall, our observations are thus best rationalized with an intrinsically low thermodynamic stability of the POTRA5 domain, requiring additional stabilizing factors to shift the conformational equilibrium towards a folded state. Specific sidechain contacts at the interface to POTRA4 provide the stabilization of folded POTRA5 in the full-length BamA protein.

Based on the finding that POTRA5 is intrinsically unfolded in all three membrane mimetics tested, a construct of the BamA transmembrane domain, BamA(421-810), with N-terminal His ${ }_{6}$-tag was prepared. This BamA construct was expressed and refolded into LDAO micelles and transferred into either bicelles or lipid bilayer nanodiscs by the established protocols. The backbone amide resonances for the transmembrane domain show a good dispersion in LDAO micelles and their position overlaps with the construct containing POTRA5 (Fig. 3a). This indicates that the barrel fold is identical in both constructs and thus independent of the presence of the unfolded POTRA5 domain. However, protein oligomerization at concentrations required for the acquisition of triple-resonance NMR spectra for backbone assignment was also observed for $\operatorname{BamA}(421-810)$ prepared in either membrane mimetic (Fig. 3c, d, right panels). Overall, the currently explored biochemical preparations thus prohibit the application of conventional backbone assignment strategies for the BamA barrel, since the sensitivity requirements for these experiments are not met. However, these preparations allow a characterization of the dynamic parts of the protein and can provide a basis for functional studies of BamA, such as protein interaction studies.

Assignment and dynamics of mobile segments of BamA(421-810) in lipid bilayer nanodiscs

For BamA(421-810), a set of 21 resonance peaks with high signal intensities was observed in each of the three membrane mimetic systems (Fig. 5a). Their narrow line width and high intensity indicates that these resonances constitute parts of BamA with a high local flexibility relative to the rest of the barrel structure. We chose to assign these residues in the lipid bilayer nanodisc mimetic, because this system represents the most native-like bilayer environment.

A $850 \mu \mathrm{M}$ sample of triple-labeled $\operatorname{BamA}(421-810)$ in nanodiscs was prepared and a 3D TROSY-HNCACB spectrum was acquired. With this spectrum, it was possible to unambiguously assign the 21 high-intensity peaks and thus identify their position in the BamA amino acid sequence as the segment D678-Q698 (Fig. 5a). Their secondary chemical shifts are close to random coil values, indicating the lack of secondary structure elements in this region. Interestingly, residues 688-690 show a tendency towards $\alpha$-helical secondary shifts (Fig. 5b). The residues D678-Q698 are part of the loop L6, which was previously identified as the lid that covers the top of the barrel on the extracellular side (Fig. 5c, d) (Gruss et al. 2013; Ni et al. 2014).

Analysis of the segment D678-Q698 in the three membrane mimetics shows that it has virtually identical chemical shifts and thus conformations in bicelles and lipid bilayer nanodiscs (Fig. S3). The differences to micelles are slightly larger, with $\Delta \delta$ values of up to $0.16 \mathrm{ppm}$ for the residues Y686 and D687. To characterize the backbone dynamics of the segment Q678-D698, we measured the relaxation rate constants ${ }^{15} \mathrm{~N}\left\{{ }^{1} \mathrm{H}\right\}-\mathrm{NOE}, R_{1}, R_{2}$, and $\eta_{\mathrm{xy}}$ at a field strength of $700 \mathrm{MHz}$ (Fig. 5e). These relaxation rate constants adopt similar values along the polypeptide segment. $R_{1}$ varies between 0.8 and $1 \mathrm{~s}^{-1}$, and $R_{2}$ between about 15 and $25 \mathrm{~s}^{-1}$ with the exception of residues 697 and 698 at the C-terminal end of the segment. The ${ }^{15} \mathrm{~N}\left\{{ }^{1} \mathrm{H}\right\}$ NOE has values between 0.2 and 0.3 , with the exception of residue 698 at the end of the segment, which has an increased NOE of 0.5 . The effective correlation times $\tau_{\mathrm{c}, \text { eff }}$ calculated from the $R_{1} / R_{2}$ ratio was 12 ns (Kay et al. 1989), and $10 \mathrm{~ns}$ from the cross-correlated cross-relaxation rate constant $\eta_{x y}$ (Lee et al. 2006). These values correspond approximately to the relaxation parameters of a freely tumbling protein with a molecular weight of about $20 \mathrm{kDa}$, which is substantially smaller than the nanodisc-embedded protein with a molecular reorientation time of typically 85 ns (Raschle et al. 2009; Yu et al. 2012). The different time scales of molecular motion and the low heteronuclear NOE indicate that segment Q678-D698 adopts a dynamic conformation relative to the barrel structure, and rationalize the high signal intensities for these resonances in the 2D $\left[{ }^{15} \mathrm{~N},{ }^{1} \mathrm{H}\right]$-TROSY spectra.

\section{Lid loop conformation in BamA proteins}

In order to rationalize the observed lid loop dynamics from a structural perspective, an alignment of Omp85 protein sequences from different Gram-negative bacteria was employed, together with a superimposition of the available crystal structures (Fig. 6). This comparison reveals an interesting finding: BamA generally features high sequence conservation among different species for the major parts of the $\beta$-barrel (Browning et al. 2013; Noinaj et al. 2013). Loop L6, however, contains an insertion region with variable insertion length in different bacterial species. The 

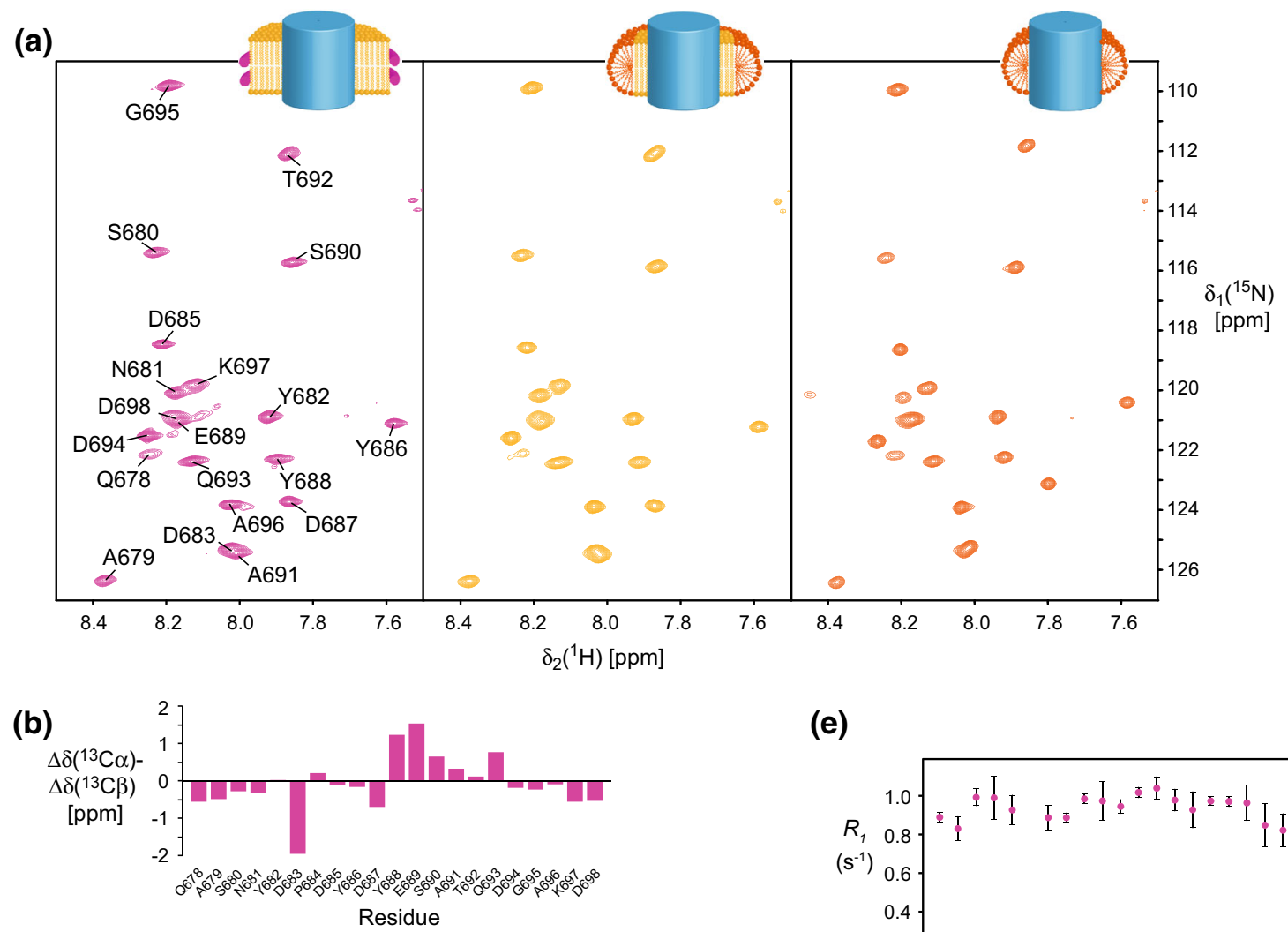

(c)

Residue

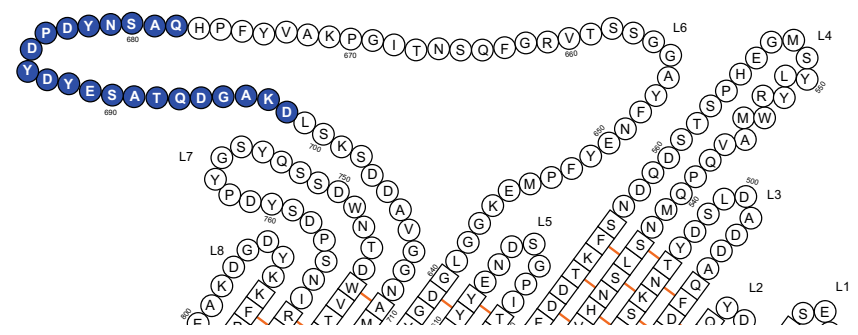

(d)

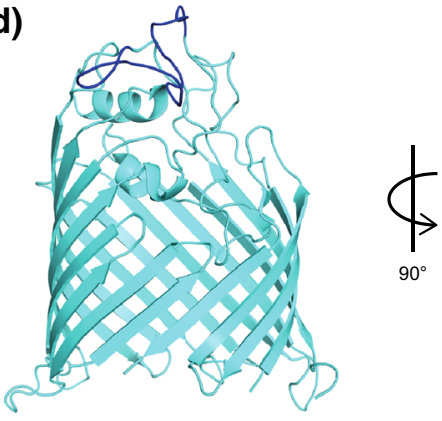

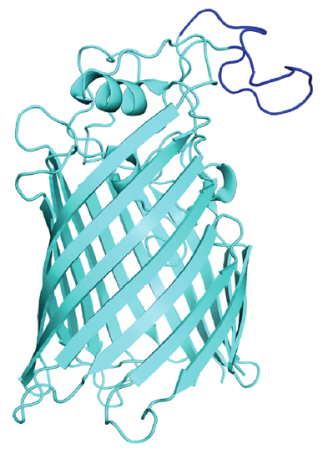

(e)

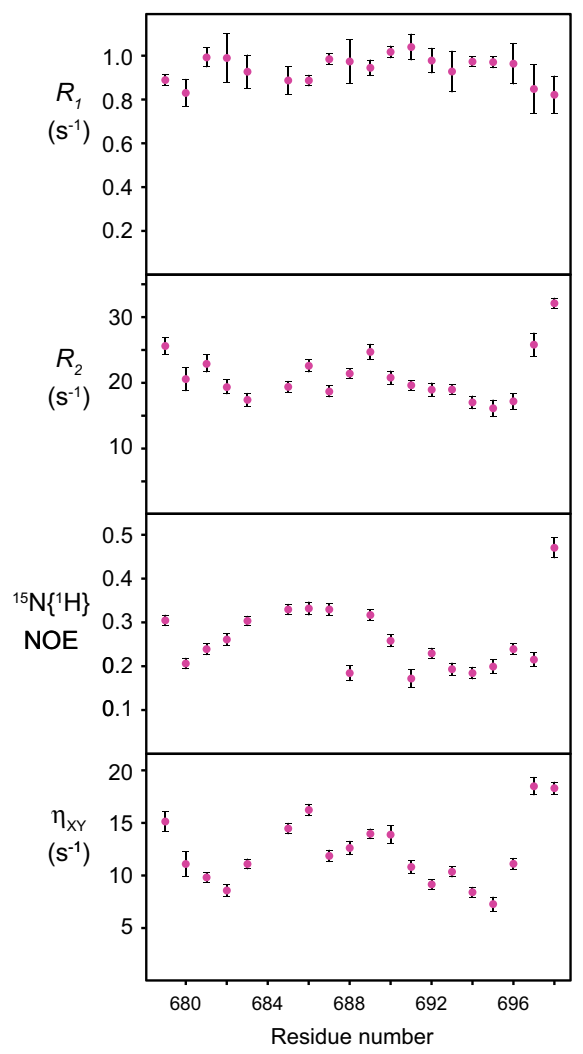

Fig. 5 Backbone dynamics of the BamA lid loop. a $2 \mathrm{D}\left[{ }^{15} \mathrm{~N},{ }^{1} \mathrm{H}\right]-$ TROSY spectra of BamA(421-810) in MSP1D1:DMPC nanodiscs (magenta), DMPC:DiC 7 PC bicelles (yellow) and LDAO micelles (orange). Sequence-specific resonance assignments are indicated. b Secondary ${ }^{13} \mathrm{C}$ chemical shifts of residues Q678-D698 of BamA(421-810) in MSP1D1:DMPC nanodiscs. $\mathbf{c}$ Enlarged view of the 2D topology plot of BamA. All residues of BamA in nanodiscs that feature high local flexibility relative to the barrel are highlighted blue. d Position of the dynamic polypeptide segment (dark blue) in the BamA crystal structure [PDB 4N75 (Ni et al. 2014)] e Sequencespecific NMR relaxation parameters of the backbone nitrogen for BamA in nanodiscs, determined at a field strength of $700 \mathrm{MHz}$ 
(a)

BAMA_ECOLI P0A940 BAMA SHISS Q3Z5I1 BAMA_VIBCJ C3NVY3 BAMA_HELPY 025369 BAMA_HELPY 025369 BAMA_HAEDU G1UBA BAMA_NEIME X5EFL5 BAMA_NEIME X5EFL5
TAMA_ECOLI POADE4
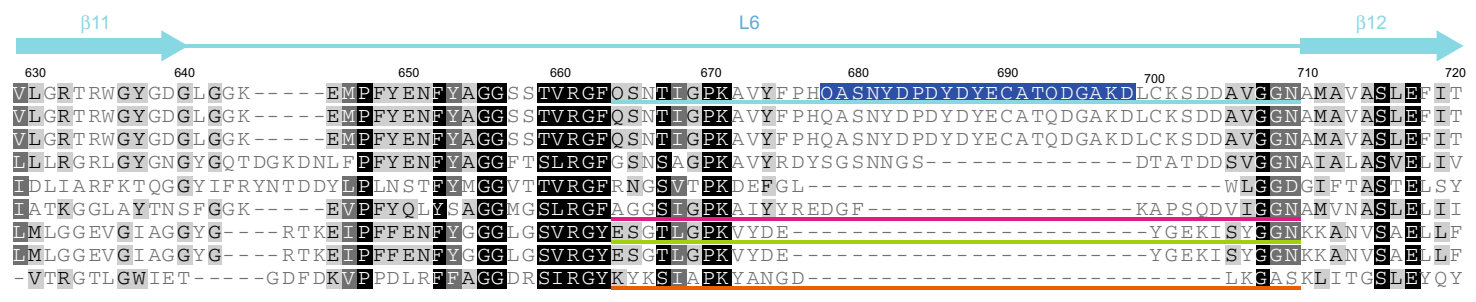

(b)

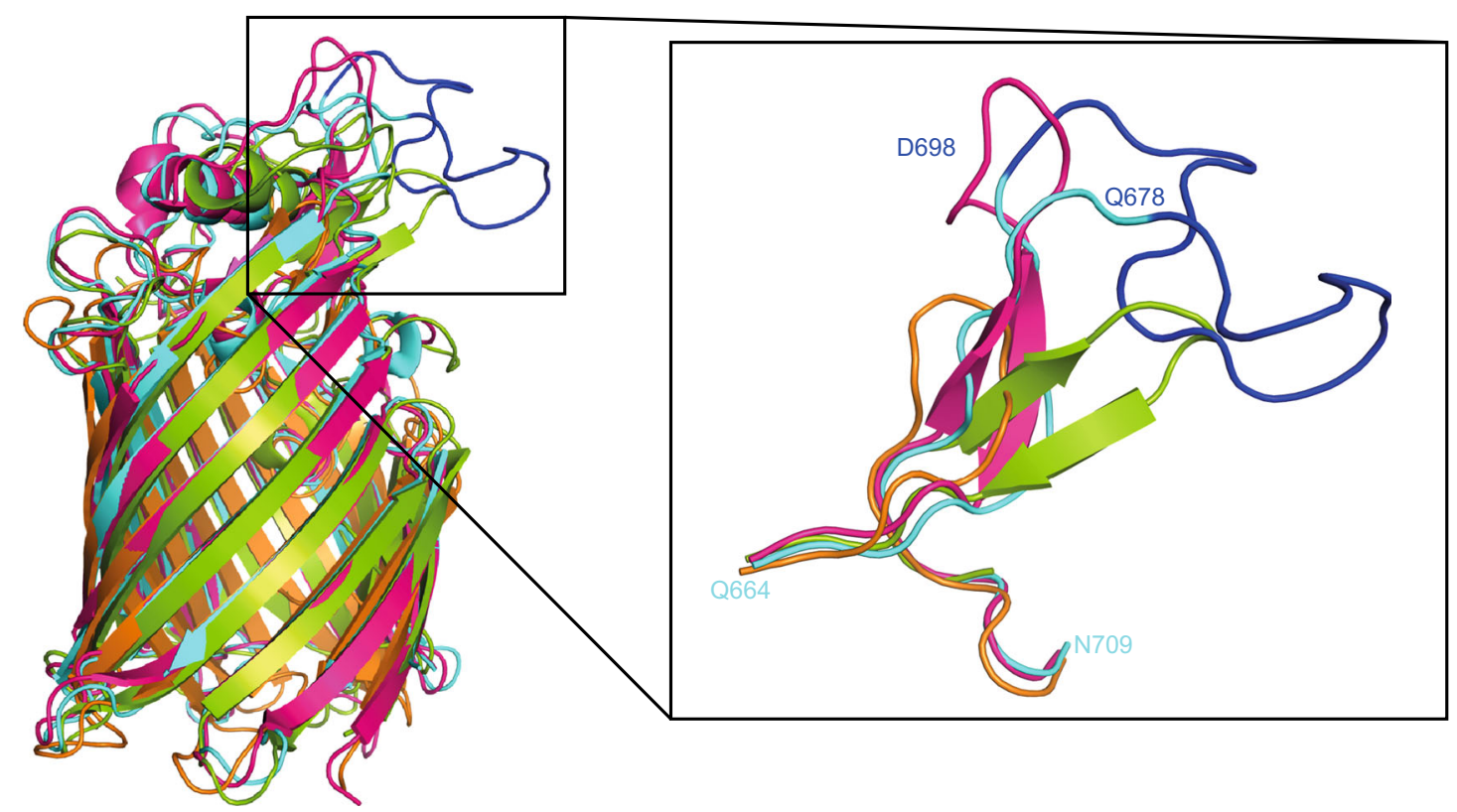

Fig. 6 Structural comparison of lid loop conformations in the Omp85 protein family. a Sequence alignment of BamA from selected Gramnegative bacteria (E. coli, S. flexneri, S. sonnei, V. cholerae, H. pylori, $H$. ducreyi, $N$. gonorrhoeae and N. meningitidis) and of TamA from E. coli. Sequences were aligned using Clustal Omega (Sievers et al. 2011). The sequence segment shown contains $\beta$-strands 11 and 12 , and the extracellular lid loop L6. Residues which are locally dynamic

residues with high local flexibility relative to the barrel structure match exactly the extent of the non-conserved loop insertion of E. coli BamA relative to other BamA sequences (Fig. 6). The dynamics thus rationalize why residues 685-697 feature poor electron density in E. coli BamA crystal structures, preventing modeling of the side chains of these residues ( $\mathrm{Ni}$ et al. 2014). High protein dynamics were similarly observed by Albrecht et al. (2014), which could not detect residues 678-693 in the structure of BamA in detergent micelles (Fig. S2). Interestingly, deletion of this loop insertion (residues 676-700) results in slower growth in E. coli (Noinaj et al. 2013), revealing that these flexible residues have a functional role in the efficiency of BamA to insert substrate proteins into the membrane. For example, they may be required for the formation of large BamA-Omp hybrid barrels, in which this part of the lid loop may temporarily be fully stretched (Gruss et al. 2013). in E. coli BamA (Fig. 5) are highlighted in dark blue. b Superimposition of available BamA and TamA crystal structures: EcBamA (PDB 4N75 (Ni et al. 2014), blue), HdBamA (PDB 4K3C (Noinaj et al. 2013), pink), $N g$ BamA (PDB 4K3B (Noinaj et al. 2013), green) and EcTamA (PDB 4C00 (Gruss et al. 2013), orange). The loop L6 insertion, corresponding to the locally dynamic residues, is highlighted in blue

In summary, the biochemical preparations reported here provide a basis for structural and functional studies of BamA by solution NMR spectroscopy. In aqueous solution, the domain POTRA5 as part of $\operatorname{BamA}(344-810)$ is unfolded, which should be taken into account for the design of biochemical experiments. The backbone dynamics of the BamA lid loop L6 in lipid bilayer nanodiscs and other membrane mimetics provide an important piece of information towards understanding the functional mechanism of the BamA insertase at the atomic level.

\section{Materials and methods}

Cloning, expression and purification of BamA

A pET30b-based expression plasmid containing E. coli BamA POTRA5 and transmembrane domain sequences 
(residues 344-810) with C-terminal $\mathrm{His}_{6}$ tag was obtained from Monika Schütz (University of Tübingen). The BamA transmembrane domain (residues 421-810) was cloned with an N-terminal $\mathrm{His}_{6}$-tag into pET15b, using NdeI and $\mathrm{XmaI}$ restriction enzymes. The QuikChange II mutagenesis protocol (Agilent Technologies Inc) was used to introduce the mutations C690S and C700S into BamA.

BamA was expressed in inclusion bodies in $E$. coli BL21 ( $\lambda$ DE3) Lemo cells in M9 minimal media (Green and Sambrook 2012) in $\mathrm{D}_{2} \mathrm{O}$ supplemented with ${ }^{15} \mathrm{NH}_{4} \mathrm{Cl}$ and D-glucose for double labeling or $\left({ }^{2} \mathrm{H},{ }^{13} \mathrm{C}\right)$-D-glucose for triple labeling, in the presence of $30 \mu \mathrm{g} / \mathrm{ml} \mathrm{kanamycin}$ (pET30b) or $100 \mu \mathrm{g} / \mathrm{ml}$ ampicillin (pET15b). Cells were grown at $37{ }^{\circ} \mathrm{C}$ until and $\mathrm{OD}_{600}$ of 0.8 an induced with $1 \mathrm{mM}$ IPTG. Cells were harvested after $5 \mathrm{~h}$ and resuspended in buffer A (50 mM TRIS-HCl pH 8.0, $300 \mathrm{mM}$ $\mathrm{NaCl}$, and $2 \mathrm{mM} \beta$-mercaptoethanol) containing lysozyme, DNAse and Complete EDTA-free protease inhibitor (Roche). Cells were lysed by French-press and centrifuged for $30 \mathrm{~min}$ at $16,000 \mathrm{~g}$. Inclusion bodies were solubilized in buffer A with $6 \mathrm{M}$ guanidine hydrochloride $(\mathrm{Gdm}-\mathrm{HCl})$ by stirring at room temperature for $1 \mathrm{~h}$ and centrifuged for $30 \mathrm{~min}$ at $16,000 \mathrm{~g}$ before being applied to a Ni-charged resin (Genscript). Ni beads were incubated with the solubilized inclusion bodies for $1 \mathrm{~h}$ while shaking. BamA was eluted with buffer A with $6 \mathrm{M} \mathrm{Gdm-HCl}$ and $200 \mathrm{mM}$ imidazole. Eluted protein was precipitated by dialysis and resuspended in buffer A with $6 \mathrm{M} \mathrm{Gdm-HCl}$. At this stage, BamA was $>95 \%$ pure with a yield of $100 \mathrm{mg}$ per liter of culture. Reducing agents were omitted in all protocols for experiments with the cysteine-free BamA mutants.

Cloning, expression, and purification of POTRA4-5(263-424)

POTRA4-5(263-424) was cloned from genomic DNA via NdeI and NotI into the pET28b expression vector (Novagen) containing a thrombin-cleavable N-terminal $\mathrm{His}_{6}$-tag. BL21( $\lambda$ DE3) pLysS cells (Novagen) were transformed with the plasmid, grown at $37{ }^{\circ} \mathrm{C}$ in M9 minimal media (Green and Sambrook 2012) in $\mathrm{H}_{2} \mathrm{O}$ supplemented with ${ }^{15} \mathrm{NH}_{4} \mathrm{Cl}$ and $\left({ }^{13} \mathrm{C}\right)$-D-glucose for double labeling, containing $30 \mu \mathrm{g} / \mathrm{ml}$ kanamycin and $50 \mu \mathrm{g} / \mathrm{ml}$ chloramphenicol to $\mathrm{OD}_{600}=0.6$, and then an additional $30 \mathrm{~min}$ at $20{ }^{\circ} \mathrm{C}$. Expression was induced by $0.4 \mathrm{mM}$ IPTG. Cells were harvested 15-18 $\mathrm{h}$ after induction, resuspended in buffer B (25 mM HEPES pH 7.5, $150 \mathrm{mM} \mathrm{NaCl}, 10 \mathrm{mM}$ imidazole, Complete EDTA-free protease inhibitor (Roche)) at a 4:1 buffer:pellet weight ratio, and lysed by 4 passes through a French press. The lysate was centrifuged for $30 \mathrm{~min}$ at $12,000 \mathrm{~g}$ at $4{ }^{\circ} \mathrm{C}$, applied to a $\mathrm{Ni}^{2+}$-HisTrap column (GE Healthcare) and eluted via an imidazole gradient. POTRA4-5(263-424) eluted at $150 \mathrm{mM}$ imidazole concentration. After overnight dialysis against buffer B without imidazole, POTRA4-5(263-424) was applied to a HiTrap Q HP column (GE Healthcare) and eluted with a $\mathrm{NaCl}$ gradient (150-500 mM). The elution fractions containing POTRA4-5 were concentrated by ultrafiltration (Vivaspin 10-kDa-cutoff concentrator, Vivascience) and subsequently applied to a gel filtration column (Superdex 75 10/300 GL, GE Healthcare) equilibrated with $25 \mathrm{mM}$ MES pH 6.5, $150 \mathrm{mM} \quad \mathrm{NaCl}$. Afterwards, POTRA4-5(263-424) was concentrated by ultrafiltration and stored at $-80{ }^{\circ} \mathrm{C}$ until usage.

Cloning, expression, and purification of POTRA5(344-424) and POTRA5-GB1

POTRA5(344-424) was cloned from genomic DNA via NdeI and NotI into the pET28b expression vector (Novagen) containing a thrombin-cleavable N-terminal $\mathrm{His}_{6}$-tag. A POTRA5-GB1 plasmid was prepared by introducing the GB1 sequence in the previous plasmid by restriction-free cloning after the POTRA5 sequence.

BL21( $\lambda$ DE3) pLysS cells (Novagen) were transformed with the plasmid, grown at $37{ }^{\circ} \mathrm{C}$ in $\mathrm{M} 9$ minimal media in $\mathrm{H}_{2} \mathrm{O}$ supplemented with ${ }^{15} \mathrm{NH}_{4} \mathrm{Cl}$, containing $30 \mu \mathrm{g} / \mathrm{ml}$ kanamycin to $\mathrm{OD}_{600}=0.6$, and then an additional $30 \mathrm{~min}$ at $25^{\circ} \mathrm{C}$. Expression was induced by $0.4 \mathrm{mM}$ IPTG. Cells were harvested 15-18 h after induction, resuspended in buffer B and lysed by French press. The lysate was centrifuged for $30 \mathrm{~min}$ at $12,000 \mathrm{~g}$ at $4{ }^{\circ} \mathrm{C}$, applied to a $\mathrm{Ni}^{2+}$. HisTrap column (GE Healthcare) and eluted via an imidazole gradient. POTRA5-GB1 eluted at $150 \mathrm{mM}$ imidazole concentration. After overnight dialysis against buffer B without imidazole, POTRA5-GB1 was applied to a HiTrap Q HP column and eluted with a $\mathrm{NaCl}$ gradient (150-500 mM). The elution fractions containing POTRA5GB1 were concentrated by ultrafiltration and subsequently applied to a gel filtration column (Superdex 75 10/300 GL) equilibrated with $25 \mathrm{mM}$ MES pH 6.5, $150 \mathrm{mM} \mathrm{NaCl}$.

\section{BamA refolding and purification in LDAO micelles}

BamA was refolded by dropwise addition to a five-fold volume of refolding buffer (50 mM TRIS-HCl $\mathrm{pH} 8$, $300 \mathrm{mM} \mathrm{NaCl}, 500 \mathrm{mM}$ Arginine and $0.5 \%$ LDAO) while stirring at $4{ }^{\circ} \mathrm{C}$. The solution was stirred overnight and then dialyzed against $20 \mathrm{mM}$ TRIS-HCl pH 8.0. Refolded BamA was applied to a HiTrap Q HP column and eluted with a $\mathrm{NaCl}$ gradient $(0-500 \mathrm{mM})$. Well-refolded protein eluted at approx. $250 \mathrm{mM} \mathrm{NaCl}$. Fractions were concentrated by ultracentrifugation (Vivaspin 30-kDa-cutoff concentrator, Vivascience) before being applied to a gel filtration column (Superdex 200 10/300 GL, GE Healthcare) equilibrated with $25 \mathrm{mM}$ MES pH 6.5, $150 \mathrm{mM}$ 
$\mathrm{NaCl}, 0.1 \%$ LDAO. The final yield of pure refolded BamA in LDAO micelles was $25 \mathrm{mg}$ per liter of culture. Samples were concentrated and the buffer was exchanged by ultracentrifugation. LDAO concentration on the samples was monitored by $1 \mathrm{D}{ }^{1} \mathrm{H}$-NMR spectroscopy and adjusted when necessary.

\section{Incorporation of BamA in DMPC: $\mathrm{DiC}_{7} \mathrm{PC}$ bicelles}

To prepare a solution of $10 \%$ DMPC:DiC ${ }_{7} P C(q=0.5)$ bicelles, $50 \mathrm{mg}$ of $\mathrm{DiC}_{7} \mathrm{PC}$ were dissolved in water and incubated for $1 \mathrm{~h}$ shaking at $30^{\circ} \mathrm{C}$, and this solution was then added to $50 \mathrm{mg}$ of DMPC and again incubated for $1 \mathrm{~h}$ shaking at $30{ }^{\circ} \mathrm{C}$. Final volume was adjusted to $1 \mathrm{ml}$ and the bicelle solution was stored at $-20{ }^{\circ} \mathrm{C}$. Refolded BamA was transferred from LDAO micelles to DMPC:DiC ${ }_{7} \mathrm{PC}$ bicelles by mixing of the protein with the bicelles at a final concentration of $2 \%$. After incubation for $1 \mathrm{~h}$ on ice, the sample was loaded on a Superdex 200 equilibrated with buffer $25 \mathrm{mM}$ MES pH6.5, $150 \mathrm{mM} \mathrm{NaCl}, 0.1 \% \mathrm{DiC}_{7} \mathrm{PC}$.

\section{Incorporation of BamA in MSP1D1:DMPC nanodiscs}

The membrane scaffold protein MSP1D1 was expressed and purified as previously described (Bayburt et al. 2002; Denisov et al. 2004; Raschle et al. 2009), and treated with TEV protease for His-tag removal yielding [MSP1D1(-)]. Small scale batches of BamA in nanodiscs were initially prepared at different MSP1D1:DMPC ratios and analyzed by size exclusion chromatography in order to obtain the highest fraction of assembled nanodiscs. An optimal ratio of 1:6:300 for BamA:MSP1D1:DMPC was determined. Refolded BamA $(20 \mu \mathrm{M})$ in LDAO micelles was incubated with MSP1D1(-) $(120 \mu \mathrm{M})$ and DMPC $(6 \mathrm{mM})$ solubilized in sodium cholate $(20 \mathrm{mM})$ for $1 \mathrm{~h}$ at room temperature in buffer $50 \mathrm{mM}$ TRIS-HCl pH 7.5, $150 \mathrm{mM} \mathrm{NaCl}, 0.5 \mathrm{mM}$ EDTA and protease inhibitors. Detergents were removed by rotating incubation with $80 \%$ (w/v) Bio-Beads SM-2 (BioRad) for $2 \mathrm{~h}$ at room temperature. Bio-Beads were removed by centrifugation and the sample was dialyzed against $50 \mathrm{mM}$ TRIS-HCl pH 7.5, $150 \mathrm{mM} \mathrm{NaCl}, 10 \mathrm{mM}$ imidazole. Empty nanodiscs were separated from nanodiscs containing BamA by Ni-affinity chromatography and further loaded on a Superdex 200 equilibrated with $25 \mathrm{mM}$ MES pH 6.5, $150 \mathrm{mM} \mathrm{NaCl}$.

\section{NMR spectroscopy}

NMR spectra were recorded at $30{ }^{\circ} \mathrm{C}$ on a Bruker Ascend 700 spectrometer equipped with a cryogenic triple-resonance probe. NMR data were processed with PROSA (Güntert et al. 1992) and analyzed with CARA and XEASY (Bartels et al. 1995). BamA samples in different conditions were analyzed by $2 \mathrm{D}\left[{ }^{15} \mathrm{~N},{ }^{1} \mathrm{H}\right]$-TROSY (Pervushin et al. 1997). For the comparison of experimental sensitivity, the measured peak intensities were normalized by the spectral acquisition parameters (as number of scans) and by the protein concentration (Wider and Dreier 2006). For the sequence-specific backbone resonance assignment of $\left[U-99 \%{ }^{2} \mathrm{H},{ }^{13} \mathrm{C},{ }^{15} \mathrm{~N}\right]-\mathrm{BamA}(344-810)$ in LDAO micelles and $\left[U-99 \%{ }^{2} \mathrm{H},{ }^{13} \mathrm{C},{ }^{15} \mathrm{~N}\right]-\operatorname{BamA}(421-810)$ in nanodiscs 3D TROSY-HNCACB (Salzmann et al. 1998) was acquired. For the resonance specific assignment of $1.3 \mathrm{mM}$ POTRA4-5(263-424) the following NMR experiments were measured at $37{ }^{\circ} \mathrm{C}:\left[{ }^{1} \mathrm{H},{ }^{15} \mathrm{~N}\right]-\mathrm{HSQC}, \mathrm{HNCA}$, HNCACB, HNCO, HNCACO. Secondary chemical shifts were calculated relative to the random-coil values of Kjaergaard and Poulsen (Kjaergaard and Poulsen 2011). For determination of the dynamic properties of $[U-99 \%$ $\left.{ }^{2} \mathrm{H},{ }^{15} \mathrm{~N}\right]-\mathrm{BamA}(421-810)$ in nanodiscs the following experiments were acquired: ${ }^{15} \mathrm{~N}-{ }^{1} \mathrm{H}$ NOE (Zhu et al. 2000), 2D $T_{1}$ (Zhu et al. 2000) and 2D TRACT (Lee et al. 2006).

Acknowledgments We thank Sina Reckel and Thomas Raschle for technical advice and discussions. This work was supported by grants from the Swiss National Science Foundation (Grant PP00P3_128419) and the European Research Council (FP7 contract MOMP 281764) to S.H. The sequence-specific resonance assignments of BamA in lipid bilayer nanodiscs (residues D678-Q698) were deposited in the BMRB (accession code 25359).

Note added in proof A characterization of BamA by combined solution and solid state NMRspectroscopy independently confirmed that the fold of POTRA5 critically depends on the interface withPOTRA4, and provides resonance assignments for parts of BamA in liposomes (Sinnige et al. J. Biomol.NMR, 2015 (published online, doi:10.1007/s10858-014-9891-6).

\section{References}

Albrecht R, Zeth K (2011) Structural basis of outer membrane protein biogenesis in bacteria. J Biol Chem 286:27792-27803

Albrecht R, Schütz M, Oberhettinger P, Faulstich M, Bermejo I, Rudel T, Diederichs K, Zeth K (2014) Structure of BamA, an essential factor in outer membrane protein biogenesis. Acta Crystallogr D 70:1779-1789

Bartels C, Xia TH, Billeter M, Güntert P, Wüthrich K (1995) The program XEASY for computer-supported NMR spectral analysis of biological macromolecules. J Biomol NMR 6:1-10

Bayburt TH, Grinkova YV, Sligar SG (2002) Self-assembly of discoidal phospholipid bilayer nanoparticles with membrane scaffold proteins. Nano Lett 2:853-856

Bos MP, Robert V, Tommassen J (2007) Functioning of outer membrane protein assembly factor Omp85 requires a single POTRA domain. EMBO Rep 8:1149-1154

Browning DF, Matthews SA, Rossiter AE, Sevastsyanovich YR, Jeeves M, Mason JL, Wells TJ, Wardius CA, Knowles TJ, Cunningham AF, Bavro VN, Overduin M, Henderson IR (2013) Mutational and topological analysis of the Escherichia coli BamA protein. PLoS One 8:e84512 
Denisov IG, Grinkova YV, Lazarides AA, Sligar SG (2004) Directed self-assembly of monodisperse phospholipid bilayer nanodiscs with controlled size. J Am Chem Soc 126:3477-3487

Dong C, Hou HF, Yang X, Shen YQ, Dong YH (2012a) Structure of Escherichia coli BamD and its functional implications in outer membrane protein assembly. Acta Crystallogr D 68:95-101

Dong C, Yang X, Hou HF, Shen YQ, Dong YH (2012b) Structure of Escherichia coli BamB and its interaction with POTRA domains of BamA. Acta Crystallogr D 68:1134-1139

Fairman JW, Noinaj N, Buchanan SK (2011) The structural biology of $\beta$-barrel membrane proteins: a summary of recent reports. Curr Opin Struct Biol 21:523-531

Gatzeva-Topalova PZ, Walton TA, Sousa MC (2008) Crystal structure of YaeT: conformational flexibility and substrate recognition. Structure 16:1873-1881

Gatzeva-Topalova PZ, Warner LR, Pardi A, Sousa MC (2010) Structure and flexibility of the complete periplasmic domain of BamA: the protein insertion machine of the outer membrane. Structure 18:1492-1501

Green MR, Sambrook JF (2012) Molecular cloning: a laboratory manual, 4th edn. Cold Spring Harbor Laboratory Press, New York

Gruss F, Zähringer F, Jakob RP, Burmann BM, Hiller S, Maier T (2013) The structural basis of autotransporter translocation by TamA. Nat Struct Mol Biol 20:1318-1320

Güntert P, Dötsch V, Wider G, Wüthrich K (1992) Processing of multi-dimensional NMR data with the new software PROSA. J Biomol NMR 2:619-629

Hagan CL, Kim S, Kahne D (2010) Reconstitution of outer membrane protein assembly from purified components. Science 328:890 892

Höhr AI, Straub SP, Warscheid B, Becker T, Wiedemann N (2015) Assembly of $\beta$-barrel proteins in the mitochondrial outer membrane. Biochim Biophys Acta 1853:74-88

Kay LE, Torchia DA, Bax A (1989) Backbone dynamics of proteins as studied by ${ }^{15} \mathrm{~N}$ inverse detected heteronuclear NMR spectroscopy: application to staphylococcal nuclease. Biochemistry 28:8972-8979

Kelly AE, Ou HD, Withers R, Dötsch V (2002) Low-conductivity buffers for high-sensitivity NMR measurements. J Am Chem Soc 124:12013-12019

Kim KH, Paetzel M (2011) Crystal structure of Escherichia coli $\mathrm{BamB}$, a lipoprotein component of the $\beta$-barrel assembly machinery complex. J Mol Biol 406:667-678

Kim S, Malinverni JC, Sliz P, Silhavy TJ, Harrison SC, Kahne D (2007) Structure and function of an essential component of the outer membrane protein assembly machine. Science 317:961964

Kim KH, Aulakh S, Tan W, Paetzel M (2011a) Crystallographic analysis of the C-terminal domain of the Escherichia coli lipoprotein BamC. Acta Crystallogr F 67:1350-1358

Kim KH, Kang HS, Okon M, Escobar-Cabrera E, McIntosh LP, Paetzel M (2011b) Structural characterization of Escherichia coli BamE, a lipoprotein component of the $\beta$-barrel assembly machinery complex. Biochemistry 50:1081-1090

Kim KH, Aulakh S, Paetzel M (2012) The bacterial outer membrane $\beta$-barrel assembly machinery. Protein Sci 21:751-768

Kjaergaard M, Poulsen FM (2011) Sequence correction of random coil chemical shifts: correlation between neighbor correction factors and changes in the Ramachandran distribution. J Biomol NMR 50:157-165

Lee D, Hilty C, Wider G, Wüthrich K (2006) Effective rotational correlation times of proteins from NMR relaxation interference. J Magn Reson 178:72-76

Leonard-Rivera M, Misra R (2012) Conserved residues of the putative L6 loop of Escherichia coli BamA play a critical role in the assembly of $\beta$-barrel outer membrane proteins, including that of BamA itself. J Bacteriol 194:4662-4668

Malinverni JC, Werner J, Kim S, Sklar JG, Kahne D, Misra R, Silhavy TJ (2006) YfiO stabilizes the YaeT complex and is essential for outer membrane protein assembly in Escherichia coli. Mol Microbiol 61:151-164

McMorran LM, Brockwell DJ, Radford SE (2014) Mechanistic studies of the biogenesis and folding of outer membrane proteins in vitro and in vivo: What have we learned to date? Arch Biochem Biophys (In press) doi:10.1016/j.abb.2014.1002.1011

Ni D, Wang Y, Yang X, Zhou H, Hou X, Cao B, Lu Z, Zhao X, Yang K, Huang Y (2014) Structural and functional analysis of the $\beta$ barrel domain of BamA from Escherichia coli. FASEB J 28:2677-2685

Noinaj N, Kuszak AJ, Gumbart JC, Lukacik P, Chang H, Easley NC, Lithgow T, Buchanan SK (2013) Structural insight into the biogenesis of $\beta$-barrel membrane proteins. Nature 501:385-390

Noinaj N, Kuszak AJ, Balusek C, Gumbart JC, Buchanan SK (2014) Lateral opening and exit pore formation are required for BamA function. Structure 22:1055-1062

Onufryk C, Crouch ML, Fang FC, Gross CA (2005) Characterization of six lipoproteins in the $\sigma^{\mathrm{E}}$ regulon. J Bacteriol 187:4552-4561

Pervushin K, Riek R, Wider G, Wüthrich K (1997) Attenuated $T_{2}$ relaxation by mutual cancellation of dipole-dipole coupling and chemical shift anisotropy indicates an avenue to NMR structures of very large biological macromolecules in solution. Proc Natl Acad Sci USA 94:12366-12371

Raschle T, Hiller S, Yu TY, Rice AJ, Walz T, Wagner G (2009) Structural and functional characterization of the integral membrane protein VDAC-1 in lipid bilayer nanodiscs. J Am Chem Soc 131:17777-17779

Rigel NW, Silhavy TJ (2012) Making a $\beta$-barrel: assembly of outer membrane proteins in gram-negative bacteria. Curr Opin Microbiol 15:189-193

Salzmann M, Pervushin K, Wider G, Senn H, Wüthrich K (1998) TROSY in triple-resonance experiments: new perspectives for sequential NMR assignment of large proteins. Proc Natl Acad Sci USA 95:13585-13590

Selkrig J, Leyton DL, Webb CT, Lithgow T (2014) Assembly of $\beta$ barrel proteins into bacterial outer membranes. Biochim Biophys Acta 1843:1542-1550

Sievers F, Wilm A, Dineen D, Gibson TJ, Karplus K, Li W, Lopez R, McWilliam H, Remmert M, Soding J, Thompson JD, Higgins DG (2011) Fast, scalable generation of high-quality protein multiple sequence alignments using clustal omega. Mol Syst Biol 7:539

Sinnige T, Weingarth M, Renault M, Baker L, Tommassen J, Baldus M (2014) Solid-state NMR studies of full-length BamA in lipid bilayers suggest limited overall POTRA mobility. J Mol Biol 426:2009-2021

Sklar JG, Wu T, Gronenberg LS, Malinverni JC, Kahne D, Silhavy TJ (2007) Lipoprotein SmpA is a component of the YaeT complex that assembles outer membrane proteins in Escherichia coli. Proc Natl Acad Sci USA 104:6400-6405

Voulhoux R, Tommassen J (2004) Omp85, an evolutionarily conserved bacterial protein involved in outer-membrane-protein assembly. Res Microbiol 155:129-135

Walther DM, Rapaport D, Tommassen J (2009) Biogenesis of $\beta$ barrel membrane proteins in bacteria and eukaryotes: evolutionary conservation and divergence. Cell Mol Life Sci 66:2789-2804

Warner LR, Varga K, Lange OF, Baker SL, Baker D, Sousa MC, Pardi A (2011) Structure of the BamC two-domain protein obtained by Rosetta with a limited NMR data set. J Mol Biol 411:83-95 
White SH (2004) The progress of membrane protein structure determination. Protein Sci 13:1948-1949

Wider G, Dreier L (2006) Measuring protein concentrations by NMR spectroscopy. J Am Chem Soc 128:2571-2576

Yu TY, Raschle T, Hiller S, Wagner G (2012) Solution NMR spectroscopic characterization of human VDAC-2 in detergent micelles and lipid bilayer nanodiscs. Biochim Biophys Acta 1818:1562-1569

Zhang H, Gao ZQ, Hou HF, Xu JH, Li LF, Su XD, Dong YH (2011) High-resolution structure of a new crystal form of BamA
POTRA4-5 from Escherichia coli. Acta Crystallogr F 67:734-738

Zhou P, Lugovskoy AA, Wagner G (2001) A solubility-enhancement tag (SET) for NMR studies of poorly behaving proteins. J Biomol NMR 20:11-14

Zhu G, Xia Y, Nicholson LK, Sze KH (2000) Protein dynamics measurements by TROSY-based NMR experiments. J Magn Reson 143:423-426 